\title{
What can managers learn online? Investigating possibilities for active understanding in the online MBA classroom.
}

\begin{abstract}
Online MBAs have become integral to business schools' portfolios and the number of MBA students opting for an online version looks set to grow. In the wake of well documented critiques of traditional MBA formats, this expansion prompted us to examine the potential for critically reflexive learning ideals in asynchronous MBA learning environments. Building the Community of Inquiry (CoI) model we elaborate elements of Bakhtin and Shotter's dialogism to develop the notion of 'active understanding' as a means to study an online MBA classroom. We present two illustrative episodes to show how aspects of active understanding may unfold and we point to the role of infrastructure, curriculum and instructor interventions in developing more genuine dialogical exchanges. Our findings suggest that online MBA course designers can learn from $\mathrm{CoI}$ approaches to which we add that critically reflexive learning is situationally sensitive; requiring the capacity to create and recognize nuance and difference in the written communication; making the other the focus of learning. We conclude with implications for pedagogy and technology infrastructure.
\end{abstract}

Keywords: Online MBA; Critical reflexivity; Bakhtin; Active Understanding.

\section{Critically reflexive learning in the online MBA}

Spearheaded by US and UK business schools, online programmes have become an integral element of higher education provision (Arbaugh and Duray, 2002; Proserpio and Gioia, 2007). MBA programmes have seen rapid conversion into online formats (Gilmore and Warren, 2007; Arbaugh et al., 2009) and online MBAs are starting to outrival their campus-based equivalents (GMAC, 2015; Financial Times, 2017).

The reasons for this growth are manifold. Online MBA students are often already acquainted with virtual work environments (McKinsey, 2015) and can benefit from the flexibility of asynchronous models when fitting learning around work (Redpath, 2012). Growing internet access and the institutionalization of Western style 
business approaches and qualifications sees MBA providers reaching into areas with developing economies. This brings opportunities where local higher education systems are less developed or where visa and travel restrictions apply. Online MBAs are beneficial for providers too, requiring few physical learning spaces and so allowing for economies of scale and scope through international pools of tutors and significantly enlarged online student bodies. One UK Business School, for instance, has 75 MBA students enrolled on campus and 1200 on its online MBA (Financial Times, 2017). The growth of online MBAs promises to compensate for the continuing decline in international student numbers on campus MBAs (e.g. CABS, 2016); a decline that is accompanied by increasingly critical judgments of MBAs and the ensuing difficulties of the MBA brand in established markets (cf., Pfeffer and Fong, 2002; Chia 2005; Hühn, 2014).

It is this rise of the online MBA through that raises with renewed importance the question of the dangers inherent in the much-critiqued techno-rational, modeldriven educational approach that underpins most MBAs (e.g. Mintzberg 2004, Ghoshal, 2005). The question is whether online MBAs can provide answers to these problems or if they merely repeat the same problems.

These concerns marked the starting point for our investigation into the potential of online MBA programmes to foster learning that is not limited to model-based abstractions and formulaic interventions but aimed at enhancing learners' reflective capacities. As a site for our study we chose an online MBA in a UK University espousing a constructivist learning pedagogy, placing discussion and reflection at the core of the learning model. Our aim is to develop an approach to study the nature of critically reflexive learning in the online MBA classroom. Whilst numerous studies, conducted over a long period of time, many of them published in this journal, have examined the nature of critical learning in on-campus MBAs (e.g. Currie and Knights, 2003; Hay and Hodgkinson, 2008), we know much less about critically reflexive approaches to virtual, text-based learning. We aim to inquire into the possibilities and limitations of the online MBA in providing a reflective space that combines knowledge and experience in relation to the real-life management problems of online learners within the wider context of the management learning literature (Shotter, 1993; Cunliffe, 2002; Chia and Holt, 2008; Cunliffe, 2008). 
We build on important work already conducted into the nature of joint learning in the online environment and, in particular, the Community of Inquiry (CoI) framework (Garrison, et al., 2000) that advances Dewey's (1933) insight that improved learning opportunities can be achieved when individual learners' interests are integrated with those of society; as a shared experience where learners explore and challenge ideas for themselves. In order to specifically investigate the question of how online MBAs can foster critically reflexive learning in text-based, 'lean' (Garrison, et.al. 2000) communicative media, we turn to the work of Bakhtin $(1981 ; 1984)$ who elaborates a version of reflective learning drawing on 'dialogism'. This specifically emphasizes learning as a process of attaining new perspectives (Shotter, 1993: 123); changes in outlook and practices (Raelin, 2007); and independent thought (Alvesson and Willmott, 1996:172). In particular, we draw on Bakhtin's (1984) notion of 'active understanding' coupled with Shotter's (2006) 'withness'- thinking to assess classroom activity and to examine how learners can engage in reflexive dialogical practice in ways that mean that they are 'struck' and moved to change their way of talking and acting to become critically reflexive practitioners (Cunliffe, 2002: 42)

\section{The nature of learning on the MBA}

Traditional MBAs have attracted sustained critique about their relevance for managerial practice (Mintzberg, 2004; Chia and Holt, 2008) and about the purpose, effects, and ethical ramifications of a higher education industry that appears to merely promote 'best practices' (Dehler et al., 2001) and other standardized management techniques (Grey, 2004). At best this may be viewed as a primary concern for rigorously developed theories with little care for the problems relevant to management practitioners (Ghoshal, 2005), at worst as a prime example of how business schools no longer develop critical thinking and intellectual curiosity (Koris et al, 2017)

The same criticisms made of traditional MBAs, that students are positioned as passive receivers of knowledge, are also levelled at online formats and this is strongly challenged by Redpath, (2012). There are suggestions that text-based communication may even be particularly favourable to the development of critical thought, as it provides more time for reflection (c.f. Garrison, et al, 2000: 90). Over the last 20 years, numerous studies have examined the nature of learning and the outcomes of online learning. Some studies measure detectable increases in the learner's ability to repeat or 
apply ideas (e.g. Arbaugh, 2001, Marks et al., 2005) while others draw more direct comparisons of grades attained and levels of learner satisfaction (e.g. Arbaugh, 2005), or examine various types of interaction i.e. learner-learner, learner-system and learnerinstructor (e.g. Arbaugh and Benbunan-Fich, 2007). Yet, while there is a significant number of papers examining the nature of online learning communities, much less is known about the critically reflexive potential online MBA programmes (Arbaugh, et al., 2013).

\section{Critical thinking, relational responsiveness, and the online classroom}

Perhaps the best-known model for studying online learning is the Community of Inquiry (CoI) framework that emphasizes, inter alia, the role of cognitive, social and teaching presence as prerequisites for positive learning experiences in inquiry-driven pedagogies (Garrison et al., 2000). Critical elements have always been part of the CoI framework (e.g. Garrison 1992). In emphasizing processes of inquiry as ways of examining ambiguities and problems, CoI builds a skeptical attitude into the struggle from doubt to belief: a 'critical optimism' holding that "conditions which exist at the moment, be they comparatively bad or comparatively good, in any event may be bettered" (Dewey, 1920: 179, in Shields, 2003: 515). Garrison (1992: 146) positions 'critical thinking' as an integral element of learning and sets out a process beginning with a self-directed learner who, prompted by an anomalous situation, engages in hypothesizing about alternatives and insights and then confirms and justifies these by acting upon them and sharing them with others. Consideration of power relations and other aspects of critical management education are therefore part of an inquiry-based curriculum: 'thinking collaboratively' (Garrison, 2015: 2), to break out of cognitive straightjackets, requires a culture of critical inquiry that supports the analysis of personal beliefs.

CoI advocates 'higher-order' thinking skills (Garrison et al., 2000: 91) in form of stage-wise processes of inquiry through which learners 'construct and confirm meaning through sustained reflection and discourse'. Following a trigger event, problems are defined and then jointly and critically explored. Meaning is constructed when diverse ideas generated in an exploratory phase are integrated so that the problem can be resolved. This conception emphasizes cognitive information exchange in a social setting that promotes openness in communication and emotional expression. Teacher 
input steers debate from questions of truth towards meaningfulness (e.g. Arbaugh, 2013).

Communal inquiry requires interpretation and self-regulation, 'finding structure in apparent disorder' (Resnick, 1987, in Fabro \& Garrison, 1998.: 46). The aim is not to develop representational knowledge, but an 'exploratory interaction with the world' (Lorino, 2011: 778): the focus always remains on making sense of and transforming situations. Such inquiries are therefore not solely problem-solving devices as the problem is not given but, triggered by an 'existential unease', the definition of the problem is part of the inquisitive process (ibid: 778). But how do learners from different backgrounds, communicating asynchronously in text format come to share any form of 'unease' and how are the differences between learners integrated into joint meaningmaking processes? How, in other words, do learners engage in critically reflexivity that embraces others and otherness so as to rethink their own understandings (Cunliffe, 2002)?

Here we turn to the work of Bakhtin, for whom dialogical meaning-making occurs as an interplay of the connection in a common world and the controversies between different discourses and genres that stem from the differences between the inhabitants of that world (Lorino et al., 2011: 780) in a continued battle between homogeneity and multiplicity of voices (Bakthin, 1981: 300). The critical potential of dialogism lies not in the cognitive processes aimed at solving, transforming or making sense of complex problems, but in how learners come to relate to differences in others while maintaining common ground.

Staying open to others' voices requires a style of thinking that is less 'about' things and more 'with' or alongside unfolding phenomena. Shotter's (2006) notion of 'withness-thinking' advocates the importance of apprehending things in their unfolding relations, so as to accompany their movement to the style of these irreversible and creative transformations in order to retain a sense of their unique character (ibid: 592). No longer populated by stable entities, the world emerges indivisibly; where what 'is' is always intimately connected to its context, so much so that others and otherness continually transform their relationally responsive forms. Such a transforming, connected, and unique world can no longer be understood and studied with tools that 
rely on mechanistic connections and representational images - it requires 'active understanding', whose development is a key element in the dialogical classroom.

Bakhtin is frequently invoked in the context of management education, for instance in relation to the role of the teacher (Ramsey, 2003; 2008) when fostering diverse and contradictory voices in the classroom (Anderson et al., 2001; Raelin, 2008), or when elaborating on participative and non-hierarchical classroom settings that facilitate collaborative learning and emphasize guidance, feedback and support (e.g. Reynolds, 1999). Studies of networked management learning also invoke Bakhtin's dialogical construction of meaning (Hodgson and Watland, 2004). Bakhtin's ideas have been employed in studies of collaborative processes in online learning environments (e.g. Mitra and Watts, 2002; Dsythe, 2002; Jones et al., 2008). Whilst not specifically focused on MBAs, they examine virtual learning environments as spaces where critical analysis and reflexivity are inherent elements of the learning approach (e.g. Ferreday et al 2006).

\section{Active understanding}

Writing against a background of Stalinist Soviet Russia governed by monological decrees and directives (DeSantis, 2001), Bakhtin pays attention to the jostling forces that make up the multiplicity of voices that constitute human exchanges. Here, language emerges as a contested site, in continual 'struggle' between uniformity and difference; negotiated on an ongoing basis, restlessly and endlessly (Holquist, 1983: 309). Bakhtin positions language and communication, as a polyphonic, living, energetic, and contested performance having the potential to embrace others and otherness in a radical, outlook-changing way (see De Man, 1983: 102).

There are many overlaps between the works of Dewey and Bakhtin (Dressman, 2004). As with CoI approaches, studies using Bakhtin's work emphasize the role of the teacher and of the social group and the fleeting, transient nature of knowledge generated. To think of relations as dynamic or dialogical, a thinking from 'within' (Shotter, 2006: 586), is not focused on bringing abstract order to the complexities of our environment but to understand these unsystematic events by appropriately relating ourselves to them; so that we can 'go on' in our practical affairs, and responsively move 
with them. Relationally responsive engagements are active: not just 'picturing' another's ideas but growing understanding by continually - actively - relating to others and their future responses in successive movements that take on their own unique character (ibid: 587; 592).

Active understanding requires attention to the peripheral and subsidiary (Ramsey, 2014); not just picturing the content of a message and aiming to fix or define those images but responding to others without fully understanding each other. Each response only ever being partially satisfactory, so that 'each utterance occasions a further response'; unfolding, living events without ever completing the picture or settling affairs (Bakhtin, 1986: 91; Shotter, 1992: 12). As we speak we must therefore ethically respect the voices of others, formulate our utterances in relation to how we feel others will respond so as to 'bridge the gaps' between our own unique positions and those of others with whom we engage not to bring order to the world, but to make new connections (ibid: 14; 19).

Studies examining face-to-face, 'real time' classrooms emphasize such active understanding, for instance by attributing importance to extended classroom debates over chats over coffee (e.g. Ramsey, 2008), to nonverbal prompts when eliciting a questioning stance, to the reading of emotive cues (e.g. Sinclair, 2007); and to gauging a learner's thought processes and guiding them further so that they become active participants in connecting theory with practice (Cunliffe, 2002; Dehler, 2009). The task of the relationally responsive teacher is to encourage dissent whilst contributing to the creation of safe spaces where students can gain confidence to venture beyond their current beliefs (Pollner, 1991). The aim is not to acquire 'some new information or data', but to redirect attention, to notice things which 'no one has doubted, but which have escaped remark only because they are always before our eyes' (Wittgenstein, in Shotter, 2006: 598).

A starting point for the analysis of dialogical relations is the 'utterance'. An uttered word will attain a meaning that is not the same in different contexts; different aspects of a word belonging to different communities of speakers, making the utterance a 'responsive-interactive unit' (Shotter, 1992: 13) that unfolds between people who, essentially, speak in different languages (Bakhtin, 1984: 271; 355). As any such exchange is unfinished, it carries its incompleteness into the not-yet of an anticipated 
response (Holquist, 1983: 314) while at the same time adding to a struggle between unifying elements of language, such as 'authoritative discourses' which denote powerful use of privileged language imposed from the outside, centralizing verbalideological thought (Bakhtin, 1986: 425), and forces that pull this unity and specificity towards decentralisation and disunification.

As dynamic and contested spaces, utterances are not determinable by abstract or structural elements of language and we have to listen out for how speakers engage with interlocutors and thereby bring an abstract and stable system of language into a concrete, specific, and meaningful realm. The directions of these relationally unfolding exchanges are shaped by many influences: broader speech genres such as typical 'business talk' and narrower, professionally stratified forms of language germane to sub-groupings - the context surrounding speech.

Utterances are therefore not individual expressions but dynamically evolving, interpersonal accomplishments (Baralou and Tsoukas, 2015) that bring into being their relational constituents. Bakhtin (1986) refers to this as 'addressivity' or, as Shotter (2005b: 9) puts it, 'the anticipatory openings we provide for those to whom we address our talk ... to reply'. Active understanding involves interlocutors sensing and responding to the 'other' be that in the form of a text, artifact or physically present person (see also Bakhtin, 1984: 293). There are also elements of represented speech, in writing, when authors provide what is referred to as a 'framing context' by assimilating others' ideas and words and making them their own. Bakhtin (1981:293) suggests that an author populates others' words 'with his [sic] intention, his own content, his own accent ... adapting it to his own semantic and expressive intentions".

Active understanding transforms authors into author-creators who understand one another by asking questions, heeding, responding or agreeing with others without descending into overly fragmented and disorientating, overwhelming and confusing levels of detailed differentiation (Bakhtin, 1981; Shotter, 1993: 62). This includes expressions of disagreement and criticism, for instance relating to social diversity (Billig, 1996) and, more broadly, the subversion of meaning (Holquist, 2002), the broadening of perspectives (Cunliffe, 2002), and the unsettling anxiety that comes with the questioning of conventional wisdom (Willmott, 1994). 
The utterance itself becomes a mode of managing and a legitimate aim for an alternative management education programme (Bureau and Komporozos-Athanasiou, 2016) aiming to understand the world not as a set of brute and mute objects with language as a tool for representation and instruction but instead drawing attention to the need to listen to the multiplicities of meanings and so to relate to and engage with the world, rather than to speak about it (Shotter, 2005a).

The question for us is whether and how an online MBA can foster active understanding in students. That these unfolding relations have to be, following Shotter's (2006: 598) reading of Wittgenstein, 'before our eyes' implies that we, as researchers, need to pay heed not only to the content of any communicative exchange, but to the ways in which such exchanges alter the relationships of those involved. Thinking from within, as interlocutor, teacher, or researcher requires "contact with an other's living being; with their utterances, with their bodily expressions, with their words, their 'works"' (Shotter, 2006: 600) - and yet these peripheral contacts are ostensibly significantly curtailed in online classrooms.

\section{Study context and method}

We investigated an online MBA programme that proposes to deliver a critical experience for learners by taking advantage of the range of students' backgrounds and perspectives in order to promote critical reflection. The degree is awarded by a UK University and delivered in collaboration with a US for-profit provider. The content of the MBA is co-written by university faculty and the private firm's learning designers and is mainly delivered by online faculty who are honorary lecturers of the university but are employed by the private firm and represented on examination and curriculum boards. Many of them hold PhDs working part-time or have portfolio careers and they are expected (and accordingly accredited, for example through AACSB) to evidence professional contributions and progress equivalent to campus-based staff.

1600 online MBA students were registered at the time of the study, from more than 124 countries and completing the programme. Student enrolment, tutor engagement, classroom tasks and student exchanges happen entirely online using group discussion and feedback but no real-time engagement. 
MBA modules are delivered in eight week blocks with reading, assignments and discussions. The learning model does not mention 'inquiry' and student tasks are not set up as investigations of specific practical issues with a phased process moving from trigger event to exploration, integration and solution. Instead, students submit an initial 750-word response to a weekly question on the discussion board which is followed up by class discussions. Discussions are facilitated and assessed by a module instructor. Students are graded on the initial response and the follow-on discussion. The discussions are therefore largely not spontaneous but prompted by assessment imperatives as students are expected to engage fully in discussion in order to gain the highest grades. Classroom participation takes place asynchronously with participants located across the world and in different time zones.

We analysed a class of initially 17 students enrolled on an 'Organization in Strategic Context' module, the second core module in the programme. This class commenced in January 2012 with 14 international students from Nigeria (4), UK (2), Mexico (2), Liberia, Denmark, Kazakhstan, Zimbabwe, the Netherlands and Egypt completing it. Nine of the participants were male and five female. The following excerpts are taken from one week in which these students generated 134 submissions in 44 threads amounting to around 40,000 words. Almost all students engaged in substantive discussions with other students or instructors and posted more than two responses to their fellow learners, participating in various threads throughout the week.

Contributions to the discussion board appear in 'threaded' form so that participants can 'click through' comments. This structure made it difficult for us to get an overview of a student's overall interactions with other learners and instructors as contributions could not be viewed in a summative way. The generally slow system also made it impossible for us (but also for instructors) to follow students' discussions in real time. As there was also no 'bulk extract' feature we could only click through each discussion, submission and tutor feedback forum manually and copy/paste contents into a Word file, manually noting time stamps and interlocutors so as to be able to reconstruct individual students' online activities. We therefore limited our in-depth review of contributions to weeks one and four in the module. We also drew on weekly reading materials, assignments, module feedback, and students' profiles. 


\section{Analysis}

We collected and read each student's contributions individually before piecing together to how they interacted with their network. Initially, we drew up depictions of networks of interactions this helped little with our aim of identifying how learners responded actively to others. We then read all threads individually to identify instances in which we felt that some elements of 'active understanding' were present. Working iteratively, and through a process of joint reading of these instances, we tried to identify active understanding and to understand how each sequence related to Bakhtin's 'framing context' (making others' words and ideas one's own), 'expression of disagreement and social diversity', and the 'questioning of (authoritative) wisdom' and we looked for instances where we felt that there was a 'privileged use of language', 'praise to authority figure and claims', and 'ways of speaking about the world' as indicators of non-active forms of understanding. We noted the instances under each of these headings. This added to our data on the learning experience of individual students in picking out particular excerpts in the posts, guided by our Bakhtinian framework of analysis.

Initially, we found it difficult to bring Bakthin's ideas to bear on the texts. The organization of discussions in threads meant that we never felt we had a grasp of the unfolding discussions as students posted in various threads in a single visit to the system while others' responses could take days, subject to time-zone differences. It was not straightforwardly 'obvious' from the texts examined whether students were actively engaged or just satisfying the weekly contribution demands.

Below we reproduce two intriguing exchanges on the discussion board, selected as they indicate the two dominant forms of exchange we observed. The first segment indicates a typical student-instructor exchange (in abridged form) prompted by the student's submission of a response to the week's discussion topic focussing on competition and Porter's Five Forces. The second is a longer chain of turns between Teri, a Brazilian, living in the UK and working in the marketing department of firm of wine merchants and Isaac, who has worked in the banking industry in Nigeria for over 10 years (pseudonyms are used). Both episodes are positive examples of learning but there are qualitative differences between them. Both excerpts exhibit aspects of 'active 
understanding' but equally, albeit for different reasons, fall short of becoming more wholesomely dialogical exchanges.

\section{Episode A: Student - Instructor exchange}

\section{A1: $7^{\text {th }}$ Jan, 2:54pm. Vince [instructor] to Teri [student]):}

[Referring to an earlier posting]

Hi Teri,

It is interesting that you quote oil and gas industry. Having access to unique minerals, metals or even markets itself makes an advantage over others and creates some kind of monopoly power. As per economics theory, no profits would come unless there is some such monopoly power.

All the best,

Vince

\section{A2: $7^{\text {th }}$ Jan, 4:14pm Vince to Teri}

Dear Vince,

I feel a little embarrassed to disagree with my instructor, but I am sure if I am wrong, you will point me to the right direction. Rivalry is a health proposal to customers, but not such a good idea for suppliers (or companies) as they will have to work harder, better the products and sometimes, lower the prices. In most countries, monopoly is illegal and fiercely fought by the government... (extends into an additional 400 word answer citing academic references and practical examples)

\section{A3: $9^{\text {th }}$ Jan, 2:12PM. Vince posts responses into Teri's original message.}

\section{(Vince:) Hi Teri,}

(quotes Teri's original message:) "I feel a little embarrassed to disagree with my instructor, but I am sure if I am wrong, you will point me to the right direction." (Vince:) You are welcome. Discussion is an important part of our learning paradigm. (quotes Teri's original message:) "Rivalry is a health proposal to customers, but not such a good idea for suppliers (or companies) as they will have to work harder, better the products and sometimes, lower the prices."

(Vince:) I have said so, where I quoted Brandenbuger \& Nalebuff"s co-optetion The five forces are supposed to push and pull so as to get more advantage for themselves and reduce one another"s profit. They do not compete in a product/market segment though. However, it is not necessary that the forces reduce one another"s profit (winlose logic). It is opposed to saving costs and improving value and the logic of coopetition of Harvard/Yale professors Brandenbuger \& Nalebuff (1997). (continues with further comments on Teri's earlier response).

(quotes Teri's original message:) In the studied case (Coke x Pepsi) the case was to Monopoly in the beginning, but it became Oligopoly (or Duopoly in some cases). I know that in principle, oligopoly's profits could never be higher than monopoly's. Although, let's not forget that Monopoly could also reduce profits (by driving away too many customers) as it happened when Brazil was only opened to Petrobras. But where will the oligopoly's profits appear?

(Vince:) This is the case of legal monopoly, not some monopoly power which causes profits. All profits are caused since you do something special or unique; even if it is 
doing something in a new context, e.g. having an Italian restaurant where there was none and there was a latent demand.

\section{A4: $9^{\text {th }}$ Jan, 4:03PM Teri (to Vince)}

Dear Vince, Uau!!! What a wonderful explanation - everything is clearer and easier now. Thanks so much for clarifying the monopolies differences - that was much appreciated and useful. I always used the term monopoly only on its legal meaning knowing there is another meaning was much helpful. I do feel I learn something (or many things) new on this course everyday and your way to instruct is very clear and pleasant - it really get through. Thanks, Teri

\section{A5: Jan, $10^{\text {th }}, 3: 29 \mathrm{pm}$ Vince (to Teri);}

Hi Teri, In fact, every human entity looks for power, i.e. control of money, resources, people, knowledge, etc. So, it is natural that each of the five forces will do so. Even a child cries to have power over you and you scold her for the same reason. All communication has the purpose of influencing others (power games). There is nothing wrong in that, unless something unethical or directly win-lose in involved. All the best

\section{Episode B: Student - Student exchange}

\section{B1: $8^{\text {th }}$ Jan, 1.35pm. Issac [student] (to Teri):}

... Please what are your views on rivalry? Would you think rivalry is a good or bad thing for an industry?

\section{B2: $8^{\text {th }}$ Jan, 4:27pm. Teri (to Isaac):}

...The profit motive which makes the rivalry may bring up the evil as well as the good.... Since shoppers always seek maximum value, only the lower price product sells, while the company's profits turn into losses. 99 times out of a 100 competition works, when it doesn't, government steps in to prevent monopolist attempts.

I believe rivalry is always a good thing to the customer, as it level and stop abusive and excessive prices and force industries to better the quality of products as well as create substitute items (ipad and tablet), but fierce rivalry such as Coke x Pepsi... can be a lost to the company as the fight for markets can influence on employees, salaries, benefits and stress itself, there can also happen a loss of an area, resulting on losses of profits and jobs (example of Rover in UK)...

\section{B3: $9^{\text {th }}$ Jan, 8:34am. Issac (to Teri):}

...I have views on rivalry pertaining to other industries such as the financial sector. Rivalry also has the tendency of blinding competitors and all they think of is enhancing market share and profitability. This is one of the reasons for the crash of the mortgage industry in the United States of America. Many customers lost their homes due to the intensity of this rivalry and crave for profitability thereby approving sub- prime mortgages. Though some were bailed out, at the end of it all, customers took the brunt of it. In this regard, I will believe rivalry may have some negatives if left unchecked and unregulated. Please what do you think? 


\section{B4: $9^{\text {th }}$ Jan, 4:39pm. Teri (to Isaac):}

...I agree with you until certain degree - rivalry can blind only the one already blinded with rage and greedy... Regarding the Mortgages in USA, what happened had nothing to do with five forces or rivalry. What happened was the crises hit USA (as it is hitting UK). All prices in everything (including salaries) went down (I don't have a raise for 3 years), therefore, the mortgages came down. Due to lack of employment and difficulty to pay off debts, banks stopped lending money so easily. - when I first came to UK all you needed to buy a house was a job, a address, name and bank account - Banks started to ask for some kind of financial stability and savings as well as deposit upfront. Sales went down, offer went up. As salaries and incomes went down as well as prices of goods, the mortgages were higher than the original price paid for. For example: I bought my house for $£ 130.000$. I still have to pay $£ 110.000$ but it now worth only $£ 106.000$ in the market. My mortgage is $£ 800$ per month. If my salary goes lower or I lose my job I won't be able to pay off my mortgage and my debt will worth more than my house. That was what happened in USA and in Portugal. People are selling houses for $£ 1.00$ just to get rid of mortgage or debt. (or late fees and taxes). It is another matter.

\section{B5: $10^{\text {th }}$ Jan, 5:05am. Isaac (to Teri):}

...While I agree that rivalry has a lot of positives in terms of service efficiency and quality of products, I am still of the opinion it can have negatives just as I outlined earlier. The relationship between rivalry and profits is still quite visible to me in the financial sector. The example I gave concerning mortgages is also very prevalent in Nigeria. We had so many banks competing to be the biggest in Nigeria in terms of profitability, balance sheet and size of assets. Due process was hardly followed in disbursing loans. This was aimed at making a lot of interest income to have the highest profits and be considered biggest bank. The lack of due process led to monumental non performing loans (bad loans) resulting in losses for most of those banks and further eroding their capital thereby running them out of the business of banking or being acquired by other banks. Now in my view, this rivalry has led to losses (or lower profits) rather than profits and this is the reason I see tendency of negative effects of tense rivalry if left unchecked. This is just my view on this and I may be wrong. Please was I able to clarify to you my view on this? Please are you opposed to this view?

\section{B6: $10^{\text {th }}$ Jan, 4:37pm. Teri (to Isaac):}

... I do understand now and have to admit that I am not up-to-date or even aware of the economy in Nigeria (I know I should be - ashamed of me - sorry!) I am a little selfish, I have to say! I involve only with south, Central and North America, Europe, China, Japan and Australia. That is my market in advertising at the moment and with all going on, I cannot find time to follow anything else - I knoooowww - I really should! Therefore I cannot give a true opinion on mortgage situation on Nigeria, so what I will do is to provide my general, although very humble opinion. I do believe we are talking about different theories here. While I spoke about coca-cola and Pepsi, jaguar, etc.. You are talking about general view of the market. It is very important to differentiate. The difference between Macroeconomics is the general view of the merchant while Microeconomics looks at the economy in details, the behaviour of individual firms, and the behaviour of individual consumers. We see things that others would not see as we look the economy for each individual detail - that is where 
the name comes from: microeconomics - looking through a microscope. [The entry continues with a lengthy summary of macroeconomic mechanisms]

\section{B7: $11^{\text {th }}$ Jan, 8:21am. Isaac (to Teri)}

$\mathrm{Hi}$

Teri,

No love lost. We all have situations peculiar to our environments. I also do not think I know that much about most countries as well. I understand your take on the relationship between rivalry and profits from the price standpoint. For instance, due to the reach of coke and Pepsi, whatever margins of profits they make may be sufficient given the fact they have a very huge consumer base. They could work together to lower prices to a level where no new entrant can dare due to high capital cost. This effectively extinguishes the threat of new entrants and external rivalry outside the 2 giants minimized. I presume this is your line of thought and I agree with you.

\section{Analysis}

Episode A shows the exchange between Teri, and her instructor, Vince. Prompted by Teri's compulsory weekly response to a discussion question, Vince elaborates on monopoly power (A1) and, without directly questioning Teri's response, invites her to further comment and expand on the issue. Teri's next message (A2) begins with a note of dissent but its tone is polite, bordering on the subservient in its acknowledgment of Vince's position of authority. Vince's later response (A3): 'You are welcome. Discussion is an important part of our learning paradigm' aims at Teri's proclaimed 'embarrassment' by encouraging discussion, but its justification as being an 'important part of the learning paradigm' remains abstract, failing to enquire into the roots of Teri's felt embarrassment; perhaps her experience of hierarchies in education or of gender roles that may contribute to her embarrassment couching her thoughts in such passive form. Vince's commentary continues in a non-personal vein (A3) when drawing on published sources and abstract definitions while Teri's response (A4): “Uau!!! What a wonderful explanation" remains adulating. Teri's does not question the authoritative claims in the literature which were given further credence by Vince by referring to them as "Harvard/Yale professors Brandenburger \& Nalebuff (1997)" [our emphasis]; Teri's latent critique of capitalism or perhaps neo-liberal world orders through her questioning of the disruptive role of competition (A2) and Vince's final comment (A5) which contains an interesting admixture of claims about power both remain unchallenged by Teri or others.

The amount of effort put into the discussions by the tutor was surprising; his responses were lengthy and detailed, stimulating and answering individual responses 
and offered for the benefit of the group without recourse to standard answers. Analysed in terms of the CoI framework's notion of 'teaching presence', Vince facilitates and focuses the discussion and shares personal meaning (Garrison and Arbaugh, 2009) but the tone often becomes authoritative.

There are detailed and questioning exchanges in Episode B. Following a series of scene-setting exchanges (B1; B2), B3 illustrates Isaac posing an open question that subtly dissents with the course content which focuses on competition as the core condition into which all organizations are thrown and the ensuing task of management to carve out and defend competitive positions. Isaac's utterance: "I will believe rivalry may have some negatives if left unchecked and unregulated. Please what do you think?" invites Teri to move outside of the frame. As the ensuing conversation indicates, Isaac's utterance veils his concern about unbridled competition whose effects he experienced in the context of Nigeria's banking sector.

In the transition from B3 to B4 we see a shift from general statements to personalized population. In contrast to Episode A, Issac and Teri relate their differences in a way that brings into play their different (heteroglot) backgrounds in a contestation of the meanings of 'rivalry', 'good' and 'bad'. The shift from Episode A to Episode B is from populating these words with factual meanings (produced by experts) towards more complex concerns and personal relevance:

"My mortgage is $£ 800$ per month. If my salary goes lower or I lose my job I won't be able to pay off my mortgage and my debt will worth more than my house. That was what happened in USA and in Portugal. People are selling houses for $£ 1.00$ just to get rid of mortgage or debt".

Here Teri translates Isaac's concerns, formulated by Isaac abstractly and tentatively ('Rivalry also has the tendency of...') into personally experienced effects; her own life being entwined with the results of an economic downturn. Neither does the comparison with the USA and Portugal appear to be drawn, in the typically structured style that was exhibited in Episode A, from the business literature (see B2, the reference to the 'Rover' example), instead they remain indicative, mere gestures towards the wider fragmentation of effects at the fringes or in the turbulence of competition. Her own situation is by no means unique, her synecdochal reference to the USA and Portugal indicating the fates of many more borrowers, but it stands against 
her overall belief in the benefits of competition and, against her insistence that it "had nothing to do with five forces or rivalry".

Isaac picks up this latent invitation to explore the frailties of competition. In B5 he reframes the topic by shifting from borrowers to mortgage lenders and the effects of competition on banks in Nigeria, using his own background as the basis for disagreement. This leads to the key sequence, B6, in which Teri first embraces Isaac's invitation. She acknowledges the other view and her own state of unknowing and even breaks with the otherwise business style language when she writes that: "I cannot find time to follow anything else - I knoooowww - I really should!”.

This exclamation indicates not just a limit of knowledge which, with more 'time' she could fix, but also to try and embrace Isaac's views. This is a watershed moment in this sequence of utterances and an example of active understanding. In what follows, Teri could either take time to explore Isaac's position or, as she does, retreat back into a mode of sameness and generalized argumentation: "Therefore I cannot give a true opinion on mortgage situation on Nigeria, so what I will do is to provide my general, although very humble opinion"

The remainder of B6 rapidly moves back into firm categories of argumentation and authoritative discourse, her exposition of macroeconomic theory closing off the momentary opening to pursue Isaac's views. Isaac's final response in B7: 'No love lost" indicates disappointment and marks the return to standard exchanges.

\section{Discussion}

Our study focuses on how 'active understanding' could be fostered in an online MBA classroom. By this we meant the transformation of authors into author-creators who understand one another by asking questions, heeding, responding or agreeing with interlocutors. We begin our assessment by revisiting the three elements of a successful CoI. First, in terms of cognitive presence, we found evidence that students welcomed new ideas; linked facts and ideas; drew boundaries and disentangled complex matters (Newman et al., 1997; Garrison, 1992). In Episode A, Teri is happy to entertain new ideas about competition and power and Episode B indicates an ability and willingness to link facts and ideas to work through complex issues. 
However rather than being animated by some trigger that unsettles the learner, Episode A remains a theoretical exchange. There is little invitation for experimentation and hypothesizing and other students do not enter at this stage, so no consensus is needed. In Episode B, two students grapple to identify an issue, both having deeper connections to the topic. In a period of three days, running almost alongside Teri and Vince's exchanges, we see Isaac and Teri (Episode B) pursuing a similar theme as Vince and Teri (Episode A), the effects of rivalry. Teri offers a neoliberal defense of liberalism with a weak, correcting state role: "99 times out of a 100 competition works, when it doesn't, government steps in..." (B2). Isaac's follow-on question, however, draws on his own banking background and a wider, abstract analysis of the financial crisis in the US and deepens this with his own experience of the Nigerian banking crisis (B5). There is a degree of exploration and an expression of difference between both students which feeds debate. There is also a sufficiently open relationship that allows for the differences to be aired.

We also find teacher presence. Over the three days in which Episode A unfolded, Vince posted over 100 comments. However, much more facilitation could have been achieved here. While the three comments to Teri $(\mathrm{A} 1,3,5)$ were thoughtful and tailored to her specific questions, they nonetheless lacked deeper engagement, at times taking on an almost parodic (Bakhtin, 1984: 324) hue, with neither participant showing any discrepancy in their speech or language; mere factual accounts regurgitating academic definitions and empty of personal relevance.

\section{Active understanding}

In terms of CoI ideals, these exchanges exhibit some degree of problem identification, exploration and integration, but the nature of a discussion question, rather than a problem focus, makes this less explicit. In terms of social presence, we found student interaction to be based on open and friendly exchanges. The instructor had a strong voice in the discussion but could have done more here.

What exactly this may be becomes clearer when we look at the episodes in terms of 'active understanding' in the learning process. In Episode A, Vince's lack of response towards the cues offered by Teri shows little engagement with her world, engendering a framing context that allows only for some trajectories of the exchange while muting others. Here, disagreements are allowed to surface only in restricted 
manner, factual quibbles over whether this or that industry is more profitable, while wider questions, such as that of the utility of such 'facts' or the trustworthiness of experts, or even the notion of profit are pushed into the background. This leaves us with a very stylized form of speech, one that is deprived of 'ideological coloration and specificity' (Bakhtin, 1984: 382) and more akin to typical MBA talk with the impress of the authoritative voice, both inscribed in the programme, the system and the instructor(s) (Bureau \& Komporozos-Athanasiou, 2016). There is little evidence that Episode A does more than elaborate abstract ideas. Where there was disagreement, as in Teri's questioning of the relationship of monopolism and profit (A2), we found a tendency to dispel any dissenting ideas by recourse to published literature or generalized definitions rather than questioning the origins of such queries or, in the above case, the 'embarrassment' that went along with dissenting.

Episode B marks an interesting juncture: both speakers have invested their comments with meaning drawn from their own worlds, the Nigerian banking crisis and the UK housing market. The abstract concept of competition which, in Vince and Teri's exchange remained academic and sterile, has taken on personal significance; the potential beginning of a dialogue between both interlocutors that goes beyond sanitized versions of speech to become personal, colourful and alive. This openness is curtailed in B6 where Teri pulls back from personal significance into abstract categorization, "I do believe we are talking about different theories here. While I spoke about coca-cola and Pepsi, jaguar, etc. You are talking about general view of the market. It is very important to differentiate." Teri resorts back to 'general, although very humble opinion', in the form of a lengthy treatise on macroeconomic principles, while Isaac's 'no love lost' marks the end of his affective involvement and a departure from speech as 'contributing to an inquiry' to merely 'participating in a conversation' (Shotter, 1992: 10); from an utterance as an event that is happening, unfolding through the interlacing of different views, back towards talk that represents the world and finalizes meaning about what something 'is'.

Perhaps most importantly, the focus on active understanding suggests that this kind of learning is not linear but happens in moment that are fleeting; the utterances that are invitations into others' lives are subtle and temporal, and that if they are not picked up (as in Episode B), that potential for dialogical relations vanishes, at least for a while. 


\section{Conclusions}

We want to draw out the implications of this study for our three areas of concern; for active understanding as a way of gauging the development of learners' critical reflexivity, for $\mathrm{CoI}$ in the context of critical management education and for online MBAs.

\section{Active understanding}

On a basic level, active understanding, which emphasizes the importance of relational responsiveness (Shotter, 2006) is evident in these online discussions. The differences between the interlocutors, their capacity to draw on their current experiences in different socio-cultural and economic backgrounds has the potential to add difference to the classroom experience. We suggest that the 'lean' (Garrison, et al. 2000) nature of text-based interactions is not a detriment to the development of dialogue. However, there are questions around the ways in which this medium allows for the expression of content as well as peripheral, subsidiary elements, in particular relating to the ongoing relationship between contributors (Shotter, 1992).

In the absence of physical gestures, facial expressions, or even the tone of voice, the ability to pick up on others' invitations for genuine dialogue rests on the ability of learners and instructors to be attentive to texts to read in more than the focal message (Ramsey, 2014). While most of our students and in particular Teri and Isaac, used language proficiently, their exchanges indicated a lack of sensitivity to others' contexts and all too often expressed a genre of abstract business talk. Teri slipping out of this mode with her expression ('I knoooowww - I really should!'), she not only acknowledges the need for care for the other's situation, but also offers an invitation to continue the dialogue. Such signals are not always easy to detect and as Isaac cannot interject at this point to offer more about his world, Teri continues her contribution by closing off the debate, rescinding her invitation.

We see that dialogue is intimate to its situation, tied to the space and time of its occurrence, to the object of the utterance and to the relationship between the interlocutors (Lorino et al., 2011 786). Shotter (2005:1) highlights the intimacy of dialogue and situation when he states that this "... kind of thinking ... can only be conducted within fleeting moments, in the course of trying to work out how best to 
respond to unique and crucial events occurring around one NOW, at this moment in time". From our study, we can conclude that active understanding involves an orientation to learning that is temporally sensitive and requires reading beyond the message in anticipation of the other's response and that such a reading of active understanding and withness-thinking extends previous research on online education. It does so by offering a means of inquiring into online discussions and by offering an insight into the potential of researching and designing online MBAs from this standpoint.

\section{Communities of Inquiry}

While the MBA programme we studied espoused a reflective pedagogy, it only partially followed the premise of a CoI. The idea of a 'critically optimistic' (Shields, 2003) inquiry, conducted by a community wrestling with unsettling issues in a profound, diverse and integrative way was only partly present in the stipulation of weekly topics and through the ensuing debates. But despite the absence of full cycles of higher-order learning processes, brought to life in such phased movements, we saw potential of relating to others dialogically, as in Episode B.

However, where CoI approaches insist that knowledge produced is tied to the specific inquiry (Lorino, et al., 2011), the classroom setting we observed retained a mix of abstract and concrete assertions. The very task of discussing competition or the Five Forces begins not with an unsettled state, but with concepts. Even the exploration of such abstractions as 'competition' can give rise to relationally reflexive dialogue when these terms are put back into ordinary use, as Wittgenstein (1997: §109) suggests. When Isaac and Teri relate competition to their own lives, they issue invitations into their worlds that are constituted by concrete, factual components and not abstractions (Shotter, 1997: 345). But all too often and also in Episode B above, attention is misdirected towards ratiocination and not the fostering of relationally-responsive dialogue.

Moving on from the CoI framework and extending its ideas that have already served the online management community well, we argue, invoking Bakhtin and Shotter's claim, that the object of an inquiry is dialogue and does not necessarily have to be a problem or solution, but the responsive landscapes created between people (ibid: 353) explored through indeterminable and unique dialogical paths. 


\section{Online MBAs}

These insights suggest that the critically reflexive potential of online MBAs can be facilitated through the move from discussions about concepts towards an appreciation of the emancipatory potential of dialogue itself. Even the very basic technology of threaded discussions used in our observed programme allowed for unfolding dialogues between learners nested in different international contexts. But these advances are mitigated by the text based, 'lean', nature of exchanges and the difficulties instructors face trying to follow unfolding interactions.

We suggest that even more emphasis should be placed on the capacity of learners and instructors to write and read in ways that allow for the expression of difference and attention towards the emerging spaces between people. The utterances that make up the online discussions are always also about the relationships between the interlocutors; they are productive of that relationship and of the potential for sharing a world. Especially given that English will not be the first language of most of the students, we wonder if enough emphasis is placed on writing and reading with an eye for difference, for nuance and for the opening up of landscapes underneath categories and abstractions. Moreover, we are not sure instructors are necessarily attuned to such conversational spaces. But even if they were, the existing technology in the form of threaded entries and the asynchronicity of responses which are posted at all times of day, coupled with the sheer number of responses an instructor has to read and produce, make it very difficult to keep abreast of the many unfolding discussions and to identify where and when to intervene. This, we acknowledge, may be a phenomenon caused by the design of the classroom under scrutiny here. As information technology infrastructures are developing we should, expect more from online classroom technologies than threaded discussion boards to allow for more vivid engagements between participants and better instructor oversight. Finally, the fostering of relationally responsive dialogue ostensibly runs against the potential of economies of scale but, as we have seen here, is still achievable. There is, therefore, hope that the rise of the online MBA does not necessarily mean a replication of the ills associated with previous incarnations of this monolith. 


\section{References}

Alvesson, M. and Willmott, H. (1996) Making Sense of Management. London: Sage.

Anderson, T., Rourke, L., Garrison, D. R. and Archer, W. (2001). Assessing Teaching Presence in a Computer Conferencing Context. Journal of Asynchronous Learning Networks, 5(2), 1-17.

Arbaugh, J. B. (2001). How Instructor Immediacy Behaviors Affect Student Satisfaction and Learning in Web-Based Courses. Business Communication Quarterly, $64(4), 42-54$.

Arbaugh, J. B. and Duray, R. (2002). Technological and Structural Characteristics Student Learning and Satisfaction with Web-based Courses: an Exploratory Study of two MBA Programmes. Management Learning, 33(3) 331-347.

Arbaugh, J. B. (2005). How Much Does "Subject Matter" Matter? A Study of Disciplinary Effects in On-Line MBA Courses. Academy of Management Learning and Education, 4 (1), 57-73.

Arbaugh, J. B. and Benbunan-Fich, R. (2007). The Importance of Participant Interaction in Online Environments. Decision Support Systems, 43 (3), 853-865.

Arbaugh, J.B. (2013) Does academic discipline moderate CoI-course outcomes relationships in online MBA courses?. The Internet and Higher Education, 17, pp.1628.

Arbaugh, J. B., DeArmond, S., and Rau, B. (2013). New Uses for Existing Tools? A Call to Study Online Management Instruction and Instructors. Academy of Management Learning \& Education, 12(4), 635-655

Arbaugh, J. B., Godfrey, M. R., Johnson, M., Pollack, B. L., Niendorf, B. and Wresch, W. (2009). Research in Online and Blended Learning in the Business Disciplines: Key Findings and Possible Future Directions. The Internet and Higher Education, 12(2), 71-87.

Bakhtin, M. M. (1981). The Dialogic Imagination: Four Essays. Edited by M. Holquist; Translated by C. Emerson and M. Holquist. 
Bakhtin, M. M. (1984). Problems of Dostoevsky's Poetics, (C. Emerson, Ed. and Trans.). Minneapolis: University of Minnesota Press.

Bakhtin, M. M. (1986). The problem of the text in linguistics, philology, and the human sciences. In Vern W. McGee, Caryl Emerson \& Michael Holquist (Trans., Eds.), Speech genres and other late essays, translated by, Austin: University of Texas Press.

Baralou, E. and Tsoukas, H., 2015. How is new organizational knowledge created in a virtual context? An ethnographic study. Organization Studies. 36(5), 593-620.

Billig, M. (1996). Arguing and Thinking: A Rhetorical Approach to Social Psychology. Cambridge: University Press.

Bureau, S.P. \& Komporozos-Athanasiou, A. (2016) Learning subversion in the business school: An 'improbable' encounter. Management Learning, online first: 1-18.

CABS (2016) 'UK business schools and international student recruitment; trends challenges and the case for change' Chartered Association of Business Schools available at https://charteredabs.org/wp-content/uploads/2016/03/Chartered-ABSInternational-Student-Recruitment-2016.pdf (accessed 5.7.17)

Chia, R. (2005). The aim of Management Education: Reflections on Mintzberg's “Managers not MBAs.” Organization Studies, 26(7), 1090-1092.

Chia, R., and Holt, R. (2008). The Nature of Knowledge in Business Schools. Academy of Management Learning \& Education, 7(4), 471-486

Cunliffe, A. L. (2002). Reflexive Dialogical Practice in Management Learning. Management Learning, 33(1), 35-61.

Cunliffe, A.L., 2008. Orientations to social constructionism: Relationally responsive social constructionism and its implications for knowledge and learning. Management Learning, 39(2), pp.123-139.

Currie, G. and Knights, D. (2003). Reflecting on a Critical Pedagogy in MBA Education. Management Learning, 34 (1), 27-49.

De Man, P. (1983). Dialogue and Dialogism. Poetics Today, 4(1), 99-107. 
Dehler, G. E. (2009). Prospects and Possibilities of Critical Management Education: Critical Beings and a Pedagogy of Critical Action. Management Learning, 40(1), 3149.

Dehler, G. E., Welsh, M. A. and Lewis, M. W. (2001) Critical Pedagogy in the `New Paradigm'. Management Learning, 32 (4), 493-511.

DeSantis, A. D. (2001). Caught between Two Worlds: Bakhtin's Dialogism in the Exile Experience. Journal of Refugee Studies, 14(1), 1-19.

Dewey, J. (1933). How we think, rev. ed. Boston: D.C. Heath.

Dressman, M. (2004) Dewey and Bakhtin in Dialogue: From Rosenblatt to a pedagogy of literature as social, aesthetic practice. In: Bakhtinian perspectives on language, literacy, and learning. Eds: Ball, A.F. \& Freedmann, S.W. Cambridge: Cambridge University Press: 34-53.

Dysthe, O. (2002) 'The Learning Potential of a Web-mediated Discussion in a University Course', Studies in Higher Education 27(3): 339-52.

Fabro, K. R., \& Garrison, D. R. (1998). Computer conferencing and higher-order learning. Indian Journal of Open Learning (1), 41-54.

Ferreday, D., Hodgson, V. and Jones, C. (2006). Dialogue, Language and Identity: Critical Issues for Networked Management Learning, Studies in Continuing Education, 28 (3), 223-239.

Financial Times (2017) 'Online MBAs: digital degrees come of age' https://www.ft.com/content/4e1934a8-f47a-11e6-95ee-f14e55513608?mhq5j=e1 (accessed 5.7.17)

Garrison, D.R. (1992) Critical thinking and self-directed learning in adult education: an analysis of responsibility and control issues. Adult Education Quarterly, 42(3): 136-148.

Garrison, D.R., Anderson, T. and Archer, W., (2002). Critical inquiry in a text-based environment: Computer conferencing in higher education. The internet and higher education, 2(2), pp.87-105. 
Ghoshal, S. (2005). Bad Management Theories are Destroying Good Management Practice. Academy of Management Learning and Education, 4 (1), 75-91.

Gilmore, S. and Warren, S. (2007). Emotion Online: Experiences of Teaching in a Virtual Learning Environment. Human Relations, 60 (4), 581-608.

Garrison, D.R. (2015) Thinking Collaboratively: Learning in a Community of Inquiry. London: Routledge.

GMAC (2015) Application Trends Annual Survey, 2015. Available at file:///C:/Users/lisa23/Downloads/2015-application-trends-web-release-1.pdf accessed 17.8.16

Grey, C. (2004). Reinventing Business Schools: the Contribution of Critical Management Education. Academy of Management Learning and Education, 3(2), 178186.

Hay, A. and Hodgkinson, M. (2008) More Success than Meets the Eye - A Challenge to Critiques of the MBA: Possibilities for Critical Management Education. Management Learning, 39(1), 21-40.

Hodgson, V, and Watland, P. (2004) 'The Social Constructionist Case for Researching Networked Management Learning' Management Learning, vol 35 (2): 125-132.

Holquist, M. (1983) Answering as authoring. Critical Inquiry 10(2): 307-319.

Holquist, M., (2002) Dialogism: Bakhtin and his world. Psychology Press.

Hühn, M.P. (2014) You reap what you sow: How MBA programs undermine ethics. Journal of Business Ethics, 121(4), p.527.

Jones, C. R., Ferreday D. and, Hodgson, V. (2008). Networked Learning a Relational Approach: Weak and Strong Ties. Journal of Computer Assisted Learning, 24(2), 90102.

Koris, R., Örtenblad, A. and Ojala, T. (2017) From maintaining the status quo to promoting free thinking and inquiry: Business students' perspective on the purpose of business school teaching. Management Learning, 48(2), pp.174-186. 
Lorino, P., Tricard, B. and Clot, Y. (2011) Research Methods for Non-Representational Approaches to Organization Studies: The Dialogical Mediated Inquiry. Organization Studies, 32(6): 769-801.

Marks, R. B., Sibley, S. D. and Arbaugh, J. B. (2005). A Structural Equation Model of Predictors for Effective Online Learning. Journal of Management Education, 29 (4), 531-563.

McKinsey (2015) 'Digital America: a tale of the haves and have-mores' http://www.mckinsey.com/industries/high-tech/our-insights/digital-america-a-tale-ofthe-haves-and-have-mores (accessed 5.7.17)

Mintzberg, H. (2004). Managers Not MBAs: A Hard Look at the Soft Practice of Managing and Management Development. Harlow: Pearson Education.

Mitra, A. and Watts, E. (2002). Theorizing Cyberspace: The Idea of Voice Applied to the Internet Discourse. New Media \& Society, 4(4), 479-498.

Newman, D.R., Johnson, C.J., Webb, B. \& Cochrane, B. (1997) Evaluating the quality of learning in computer supported co-operatvie learning. Journal of the American Society for Information Exchange, 48(6): 484-495.

Pfeffer, J. and Fong, C.T. (2002) The End of Business Schools? Less Success than Meets the Eye. Academy of Management Learning \& Education, 1(1): 78-95.

Pollner, M. (1991). Left of Ethnomethodology: The Rise and Decline of Radical Reflexivity. American Sociological Review, 56, 370-380.

Proserpio, L., and Gioia, D. A. (2007). Teaching the Virtual Generation. Academy of Management Learning \& Education, 6(1), 69-80.

Raelin, J. A. (2007). Toward an Epistemology of Practice. Academy of Management Learning \& Education, 6(4), 495-519.

Raelin, J. A. (2008). Emancipatory Discourse and Liberation. Management Learning, 39(5), 519-540.

Ramsey, C. (2003). Using Virtual Learning Environments to Facilitate New Learning Relationships. The International Journal of Management Education, 3(2), 31-41. 
Ramsey, C. (2008). Managing to Learn: The Social Poetics of a Polyphonic 'Classroom'. Organization Studies, 29(4), 543-558.

Ramsey. C. (2014) Management Learning: A Scholarship of Practice Centred on Attention? Management Learning, 45(1): 6-20.

Redpath, L. (2012). Confronting the Bias against On-line Learning in Management Education. Academy of Management Learning \& Education, 11(1), 125-140. 231

Reynolds, M. (1999). Grasping the Nettle: Possibilities and Pitfalls of a Critical Management Pedagogy. British Journal of Management, 10(2), 171-184.

Shields, PM. (2003) The community of inquiry: classical pragmatism and public administration. Administration \& Society, 35(5): 510-538.

Shotter, J. (1992) Bakhtin and Billing: Monological versus Dialogical Practices. American Behavioral Scientist, 36(8): 8-23.

Shotter, J. (1993). Conversational Realties; Constructing Life through Language. London; SAGE

Shotter (1997) Dialogical Realities: The Ordinary, the Everyday, and other strange New Worlds. Journal for the Theory of Social Behaviour, 27(2/3): 345-358.

Shotter, J. (2005a) 'Inside the Moment of Managing': Wittgenstein and the Everyday Dynamics of our Expressive-Responsive Activities. Organization Studies 26(1): 113135.

Shotter, J. (2005b) The short book of 'withness'-thinking' London: KCCF

Shotter, J., (2006) Understanding process from within: An argument for 'withness'thinking. Organization Studies, 27(4), pp.585-604.

Sinclair, A. (2007). Teaching Leadership Critically to MBAs Experiences from Heaven and Hell. Management Learning, 38(4), 458-472.

Willmott, H. (1994). Management Education: Provocations to a Debate. Management Learning, 25(1), 105-136.

Wittgenstein, L. (1997/1953) Philosophical Investigations. Oxford: Blackwell. 
